\title{
NIR-laser-induced selective rotamerization of hydroxy conformers of cytosine $\dagger$
}

\author{
Leszek Lapinski, ${ }^{a}$ Maciej J. Nowak, ${ }^{* a}$ Igor Reva, $^{b}$ Hanna Rostkowska ${ }^{a}$ and Rui Fausto ${ }^{b}$
}

Received 9th April 2010, Accepted 7th June 2010

DOI: $10.1039 / \mathrm{c0cp00177e}$

The relative populations of two amino-hydroxy conformers of cytosine, differing in rotation of the $\mathrm{OH}$ group by $\sim 180^{\circ}$, were selectively and repeatedly manipulated with narrowband, near-infrared laser light. For cytosine monomers isolated in a low-temperature Ar matrix, laser irradiations at $7013 \mathrm{~cm}^{-1}$ and at $7034 \mathrm{~cm}^{-1}$ were found to induce effective transformations of the two conformers into each other.

Near-IR irradiation can induce conformational changes in small molecules isolated in cryogenic matrices. ${ }^{1}$ However, these phenomena have not been reported for larger heterocyclic molecules, such as cytosine. In polyatomic molecules containing more than 10 atoms, the higher density of vibrational states may affect the pathways of vibrational energy redistribution and hence the efficiency of rotational isomerization stimulated by excitation of the overtones of stretching vibrations.

The amino-hydroxy (AH) form of cytosine (see Scheme 1) is the most stable tautomer of the monomeric compound. This tautomer was theoretically predicted to be more stable (by $4.9-6.3 \mathrm{~kJ} \mathrm{~mol}^{-1}$ ) than the amino-oxo (AO) form ${ }^{2}$ and was experimentally found, using microwave ${ }^{3}$ and photoelectron ${ }^{4}$ techniques, to be a dominating species in the gas phase. The $\mathbf{A H}$ tautomer is also the most populated form in low-temperature matrices ${ }^{5}$ and helium nanodroplets, ${ }^{6}$ as revealed by IR spectroscopy.

Two conformers of the amino-hydroxy form of cytosine are possible (Scheme 1). They differ in rotation of the hydroxyl group by $c a .180^{\circ}$. According to theoretical calculations, ${ }^{2}$ the energy difference between the two conformers is $2.9-3.1 \mathrm{~kJ} \mathrm{~mol}^{-1}$ (in favor of $\mathbf{A H 1}$ ); hence the $\mathbf{A H 1}: \mathbf{A H 2}$ ratio in the gas phase (at $495 \mathrm{~K}$ ) should be $\sim 2.1: 1$. Both amino-hydroxy conformers were recently identified for cytosine monomers trapped in helium nanodroplets at $0.37 \mathrm{~K} .{ }^{6}$ This result shows that no rapid conformational cooling occurs for $\mathbf{A H 1}$ and $\mathbf{A H 2}$ forms. In the current communication, we report the first experimental observation of the interconversion of $\mathbf{A H 1}$ and $\mathbf{A H 2}$ forms of cytosine induced by near-IR narrowband laser light. The matrixisolation technique was used for this purpose.

To prepare a low-temperature Ar matrix containing cytosine monomers, a sample of the solid compound (Sigma-Aldrich) was heated in a miniature glass oven to

${ }^{a}$ Institute of Physics, Polish Academy of Sciences, Al. Lotnikow 32/46, 02-668 Warsaw, Poland. E-mail: mjnowak@ifpan.edu.pl

${ }^{b}$ Department of Chemistry, University of Coimbra, 3004-535 Coimbra, Portugal

$\dagger$ Electronic supplementary information (ESI) available: Full mid-IR spectra of cytosine recorded after: (i) deposition of an Ar matrix; (ii) irradiation at $7013 \mathrm{~cm}^{-1}$; (iii) irradiation at $7034 \mathrm{~cm}^{-1}$. See DOI: $10.1039 / \mathrm{c} 0 \mathrm{cp} 00177 \mathrm{e}$

ca. $495 \mathrm{~K}$. The vapors of cytosine were deposited together with a large excess of argon on a CsI window mounted at the cold $(12 \mathrm{~K})$ tip of a helium-cooled cryostat. Mid-IR absorption spectra were recorded using a Thermo Nicolet 670 FTIR spectrometer equipped with a $\mathrm{KBr}$ beam splitter and a DTGS detector. Near-IR spectra were recorded using the same spectrometer but equipped with $\mathrm{a} \mathrm{CaF}_{2}$ beam splitter and an InGaAs detector. Monomers of cytosine isolated in an $\mathrm{Ar}$ matrix were irradiated using a narrowband, tunable near-IR light emitted by a Quanta-Ray MOPO-SL pulsed optical parametric oscillator (FWHM $\sim 0.2 \mathrm{~cm}^{-1}$, repetition rate $10 \mathrm{~Hz}$, pulse energy $\sim 3 \mathrm{~mJ}$ ) pumped with a pulsed Spectra-Physics Quanta-Ray PRO-230-10 Nd:YAG laser.

A fragment of the near-IR spectrum of cytosine monomers isolated in an Ar matrix is presented in Fig. 1. Absorption bands observed in the $7100-6700 \mathrm{~cm}^{-1}$ range are due to overtones of the stretching vibrations of the $\mathrm{OH}$ and $\mathrm{NH}$ groups. Narrowband, near-IR irradiations at different wavelengths, corresponding to the overtone absorptions (shown in Fig. 1), were carried out. The changes induced on the populations of AH1 and AH2 forms were monitored by observation of the mid-IR spectra of the matrix-isolated cytosine monomers. The irradiations at 7034 and $7013 \mathrm{~cm}^{-1}$ were found to be particularly effective. Upon irradiation at $7013 \mathrm{~cm}^{-1}$, the initially mostpopulated AH1 conformer converted into AH2, whereas upon irradiation at $7034 \mathrm{~cm}^{-1}$ a transformation of $\mathbf{A H 2}$ into $\mathbf{A H 1}$ was observed. The full mid-IR absorption spectrum collected before any irradiation as well as the spectra recorded after irradiations at 7034 and $7013 \mathrm{~cm}^{-1}$ are shown in Fig. S1 (in the ESI $\dagger$ ). Fragments of the mid-IR spectra recorded after each of these irradiations are presented in Fig. 2. By performing successive cycles of near-IR $\left(7034,7013 \mathrm{~cm}^{-1}\right)$ irradiation, we have experimentally proven that the population of the amino-hydroxy tautomer can be transferred many times between $\mathbf{A H 1}$ and $\mathbf{A H 2}$ without any loss of the total amount (Scheme 2).

The assignment of the experimentally observed IR bands to AH1 and AH2 forms of cytosine is confirmed by comparison (see Fig. 2) with the band positions theoretically predicted at the

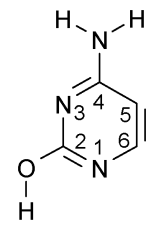

AH1<smiles>Nc1nccc(O)n1</smiles>

AH2<smiles>Nc1cc[nH]c(=O)n1</smiles>

AO<smiles>N=c1cc[nH]c(=O)[nH]1</smiles>

10
Scheme 1 The structures of: two rotamers of the amino-hydroxy (AH1 and AH2), the amino-oxo (AO) and the imino-oxo (IO) forms of cytosine. 


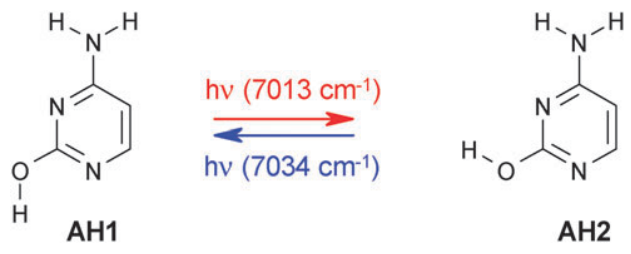

Scheme 2 The effects of near-IR irradiations.

DFT(B3LYP) $/ 6-31++\mathrm{G}(\mathrm{d}, \mathrm{p})$ level using the GAUSSIAN 03 program. ${ }^{7}$ The two bands observed at 3601 and $3591 \mathrm{~cm}^{-1}$ are due to the stretching vibrations of the hydroxyl group $\nu(\mathrm{OH})$ in $\mathbf{A H 2}$ and AH1 conformers, respectively. In both conformers, the hydrogen atom of the $\mathrm{OH}$ group interacts with a nitrogen atom placed in an $\alpha$ position in the pyrimidine ring. Therefore, the closest vicinity of the $\mathrm{OH}$ group is very similar in both conformers. Only the presence of the amino group in the $\beta$ position is the reason for different frequencies of the $\nu(\mathrm{OH})$ bands and different energies of $\mathbf{A H 1}$ and $\mathbf{A H 2}$. Whereas in AH2 the $\mathrm{OH}$ group competes with $\mathrm{NH}_{2}$ for the density of the $\mathrm{N} 3$ lone electron pair, in AH1 the $\mathrm{OH}$ group can interact with the density of the N1 lone electron pair without any competitor. As a consequence, the $\mathrm{OH}$ group in $\mathbf{A H 1}$ is involved in a stronger intramolecular interaction. This makes the energy of AH1 and the frequency of the $\nu(\mathrm{OH})$ vibration in this form lower than the respective parameters of AH2. The current assignment of the bands at 3601 and $3591 \mathrm{~cm}^{-1}$ to $\mathbf{A H 2}$ and AH1, respectively, is in agreement with the results of the studies of cytosine monomers in helium nanodroplets, ${ }^{6}$ where the corresponding absorptions were observed at 3618 and $3610 \mathrm{~cm}^{-1}$.

The observed frequency difference of the $\nu(\mathrm{OH})$ bands in AH2 and AH1 $\left(10 \mathrm{~cm}^{-1}\right.$ in Ar matrix and $8 \mathrm{~cm}^{-1}$ in $\mathrm{He}$ nanodroplets) ${ }^{6}$ is in agreement with the theoretically calculated value of $6 \mathrm{~cm}^{-1}$. A larger difference $\left(12 \mathrm{~cm}^{-1}\right)$ is predicted for normal modes in AH1 and AH2 with frequencies of $c a$. $1430 \mathrm{~cm}^{-1}$. These modes have significant contribution of the stretching vibration of the $\mathrm{C}-\mathrm{O}$ bond. In the experimental spectrum of cytosine isolated in an Ar matrix, the corresponding bands, found at $1439 \mathrm{~cm}^{-1}$ and $1428 \mathrm{~cm}^{-1}$, are separated by $11 \mathrm{~cm}^{-1}$ (see Fig. 2).

The region below $3000 \mathrm{~cm}^{-1}$ was not observed in the investigation of cytosine in He nanodroplets. ${ }^{6}$ Because of the structural similarity of forms AH1 and AH2, many other mid-IR bands due to these two forms are experimentally found and theoretically predicted at frequencies differing only by $2-3 \mathrm{~cm}^{-1}$ or less. This is the case for the bands observed at

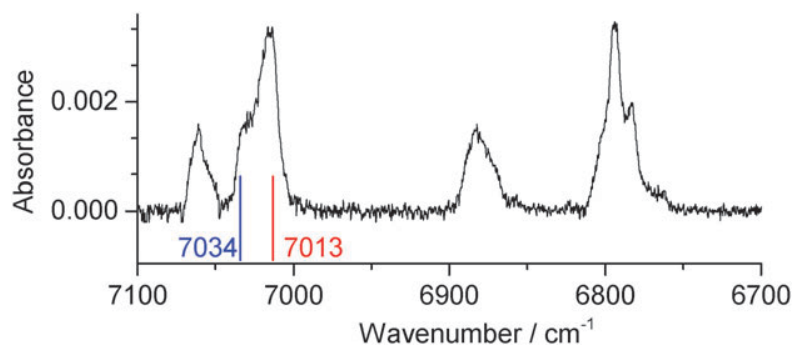

Fig. $17100-6700 \mathrm{~cm}^{-1}$ region of the near-IR spectrum of cytosine isolated in an Ar matrix.
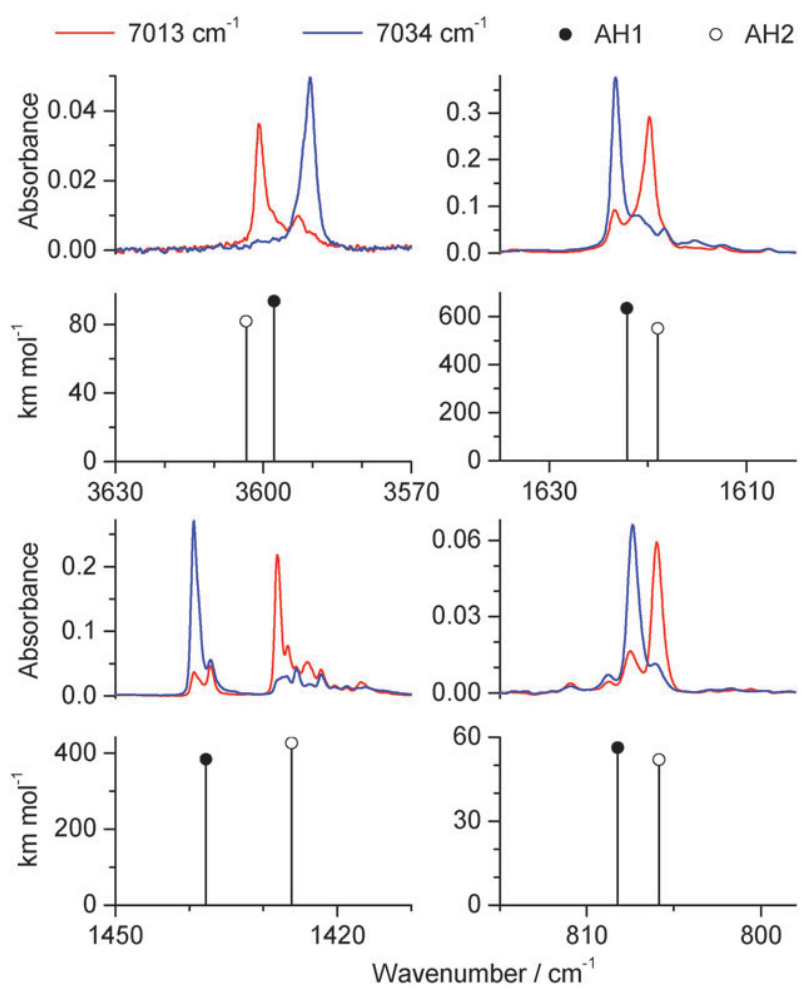

Fig. 2 Fragments of the IR spectra of cytosine isolated in an $\mathrm{Ar}$ matrix: (red) after irradiation at $7013 \mathrm{~cm}^{-1}$; (blue) after irradiation at $7034 \mathrm{~cm}^{-1}$; compared to the IR spectra calculated for AH1 and AH2 conformers at the DFT(B3LYP)/6-31++G(d,p) level. The calculated wavenumbers were scaled by 0.950 (above $3000 \mathrm{~cm}^{-1}$ ), by 0.976 (for the $3000-1000 \mathrm{~cm}^{-1}$ range) and by 0.993 (below $1000 \mathrm{~cm}^{-1}$ ).

1623 and $1620 \mathrm{~cm}^{-1}$ (theoretical frequency difference $3 \mathrm{~cm}^{-1}$ ) and for the bands found at 807.4 and $806.0 \mathrm{~cm}^{-1}$ (theoretical frequency difference $2 \mathrm{~cm}^{-1}$ ), see Fig. 2. The general agreement between the experimentally observed and theoretically predicted frequency differences strongly supports the assignment of the two sets of bands to the two $\mathbf{A H 1}$ and $\mathbf{A H 2}$ rotamers of the amino-hydroxy tautomer of cytosine.

Alongside the two sets of bands assigned to AH1 and AH2, which were identified on the basis of large-scale intensity changes induced by irradiations at 7013 and $7034 \mathrm{~cm}^{-1}$ (see Fig. 2 and 3), a third group of mid-IR bands was also observed in the spectrum of matrix-isolated cytosine. The bands belonging to this group (marked with asterisks in Fig. 3 and 4) did not change their intensities upon any near-IR irradiations. These bands are due to the amino-oxo (AO) or imino-oxo (IO) tautomers of cytosine, which are also populated (though in smaller amounts) in the matrix-isolated sample.

In the frequency range $3650-3400 \mathrm{~cm}^{-1}$ (Fig. 4), the only absorptions due to $\mathbf{A H 2}$ and AH1 forms, which neither overlap significantly with each other nor with the bands attributed to other tautomers, are the bands corresponding to $\nu(\mathrm{OH})$ vibrations, found at 3601 and $3591 \mathrm{~cm}^{-1}$ (bands 1 and 2). The band observed at $3445 \mathrm{~cm}^{-1}$ (band 7) is a nearly perfect overlap of the absorptions resulting from the symmetric $\mathrm{NH}_{2}$ stretching vibrations $\nu_{\mathrm{s}}\left(\mathrm{NH}_{2}\right)$ in both amino-hydroxy conformers. The antisymmetric $\mathrm{NH}_{2}$ stretching vibrations 


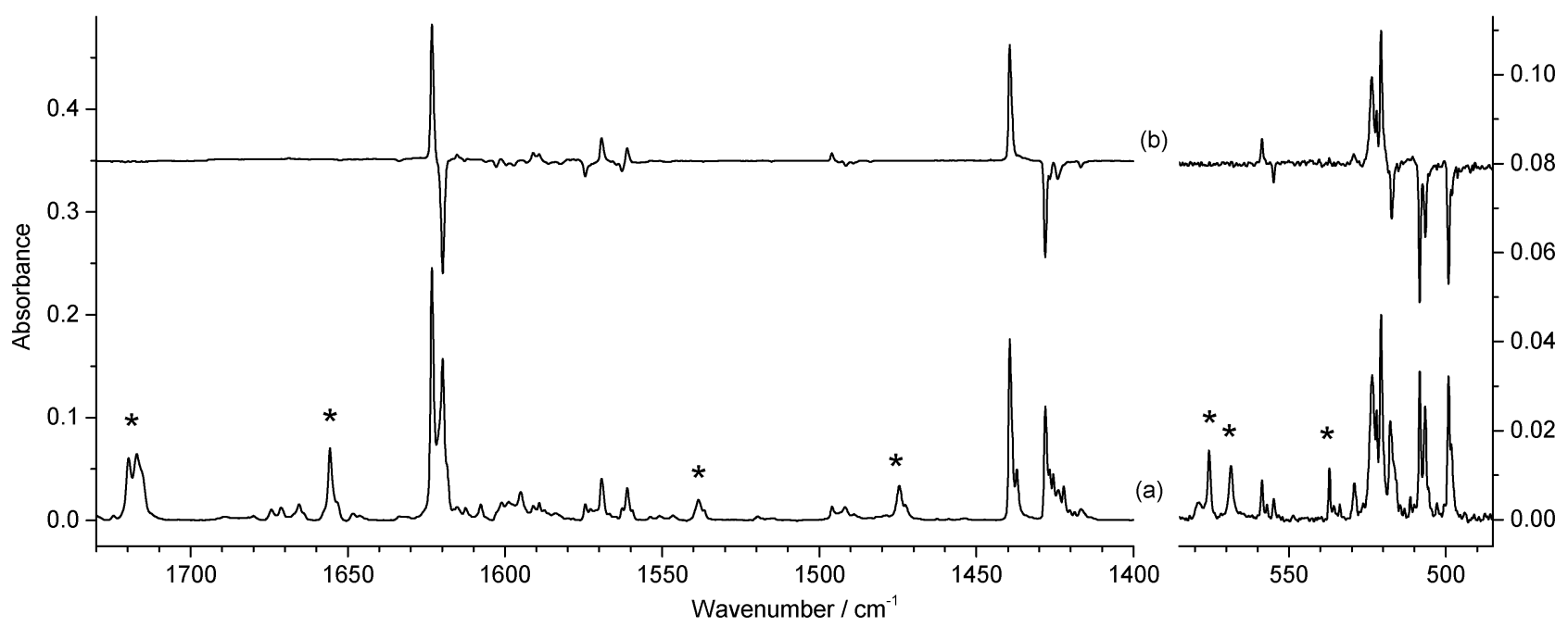

Fig. 3 Fragments of the IR spectra of cytosine isolated in an Ar matrix: (a) recorded after deposition of the matrix; (b) subtraction result: the spectrum recorded after irradiation at $7034 \mathrm{~cm}^{-1}$ minus spectrum (a). Asterisks indicate the bands not affected by either $7034 \mathrm{~cm}^{-1} \mathrm{or} 7013 \mathrm{~cm}^{-1}$ irradiation.

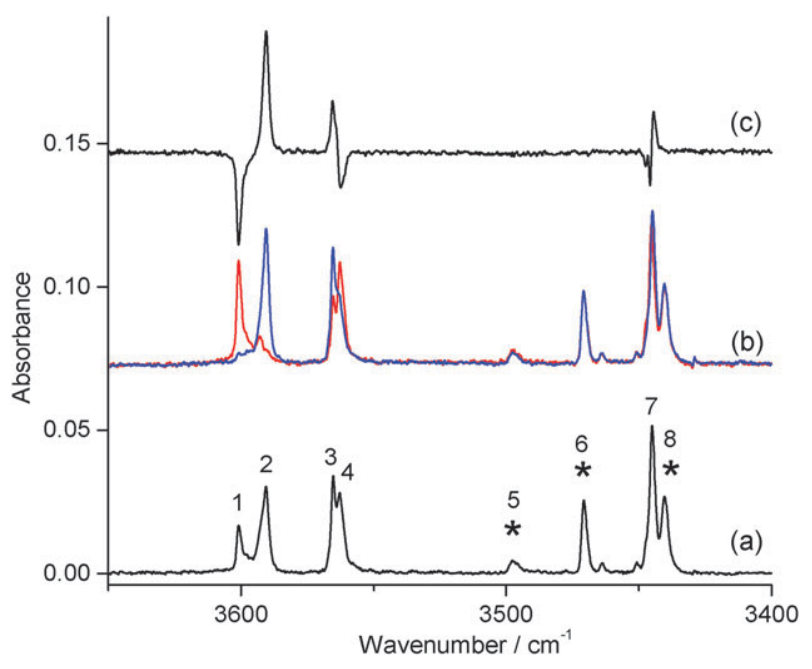

Fig. 4 Part of the spectra of cytosine isolated in an Ar matrix: (a) recorded after deposition of the matrix; (b) red trace: after irradiation at $7013 \mathrm{~cm}^{-1}$, blue trace: after irradiation at $7034 \mathrm{~cm}^{-1}$; (c) subtraction result: the spectrum recorded after irradiation at $7034 \mathrm{~cm}^{-1}$ minus the spectrum recorded after irradiation at $7013 \mathrm{~cm}^{-1}$. Asterisks indicate the bands not affected by either $7034 \mathrm{~cm}^{-1}$ or by $7013 \mathrm{~cm}^{-1}$ irradiation. The numbered bands are due to the following vibrations: (1) $-\nu(\mathrm{OH})$ in AH2, (2) $-\nu(\mathrm{OH})$ in AH1, (3) $-\nu_{\mathrm{a}}\left(\mathrm{NH}_{2}\right)$ in AH1, (4) $-\nu_{\mathrm{a}}\left(\mathrm{NH}_{2}\right)$ in $\mathbf{A H 2},(5)-\nu(\mathrm{NH})$ in $\mathbf{I O},(6)-\nu(\mathrm{N} 1 \mathrm{H})$ in $\mathbf{A O},(7)-\nu_{\mathrm{s}}\left(\mathrm{NH}_{2}\right)$ in both $\mathbf{A H 1}$ and $\mathbf{A H 2}$ (partially overlapping), (8)- $\nu_{\mathrm{s}}\left(\mathrm{NH}_{2}\right)$ in $\mathbf{A O}$. The band due to the $\nu_{\mathrm{a}}\left(\mathrm{NH}_{2}\right)$ vibration in $\mathbf{A O}$ form is hidden under bands (3) and (4).

$\nu_{\mathrm{a}}\left(\mathrm{NH}_{2}\right)$ in $\mathbf{A H 1}$ and $\mathbf{A H 2}$ have somewhat more distinct frequencies 3565 and $3563 \mathrm{~cm}^{-1}$ (bands 3 and 4 in Fig. 4). Other bands observed in the $3650-3400 \mathrm{~cm}^{-1}$ region do not change their intensities and shapes upon near-IR irradiation. Two of these bands are the spectral signatures of the amino-oxo (AO) tautomeric form and can be assigned to the $\nu(\mathrm{N} 1 \mathrm{H})$ (3471 $\mathrm{cm}^{-1}$, band 6) and symmetric $\nu_{\mathrm{s}}\left(\mathrm{NH}_{2}\right)\left(3440 \mathrm{~cm}^{-1}\right.$, band 8$)$ vibrations, whereas the low-intensity band at $3497 \mathrm{~cm}^{-1}$ (band 5 in Fig. 4) is the sole spectral manifestation of the minor imino-oxo (IO) form observed in this spectral range.

In conclusion, two amino-hydroxy conformers of cytosine were shown to undergo mutual conversions selectively induced by narrowband near-IR laser light. It was also demonstrated that other forms of cytosine (amino-oxo and imino-oxo) are not affected by near-IR irradiation. We believe that a variety of conformational isomerizations in heterocyclic molecules can be controlled using an analogous approach.

\section{References}

1 M. Pettersson, J. Lundell, L. Khriachtchev and M. Räsänen, J. Am. Chem. Soc., 1997, 119, 11715-11716; E. M. S. Maçôas, L. Khriachtchev, M. Pettersson, R. Fausto and M. Räsänen, J. Am. Chem. Soc., 2003, 125, 16188-16189; A. Sharma, I. Reva and R. Fausto, J. Am. Chem. Soc., 2009, 131, 8752-8753.

2 G. Fogarasi, J. Phys. Chem. A, 2002, 106, 1381-1390; M. Piacenza and S. Grimme, J. Comput. Chem., 2004, 25, 83-98; S. A. Trygubenko, T. V. Bogdan, M. Rueda, M. Orozco, F. J. Luque, J. Sponder, P. Slavicek and P. Hobza, Phys. Chem. Chem. Phys., 2002, 4, 4192-4203; R. Kobayashi, J. Phys. Chem. A, 1998, 102, 10813-10817; J. K. Wolken, Ch. Yao, F. Turecek, M. J. Polce and Ch. Wesdemiotis, Int. J. Mass Spectrom., 2007, 267, 30-42.

3 R. D. Brown, P. D. Godfrey, D. McNaughton and A. P. Pierlot, J. Am. Chem. Soc., 1989, 111, 2308-2310.

4 V. Feyer, O. Plekan, R. Richter, M. Coreno, G. Vall-llosera, K. C. Prince, A. B. Trofimov, I. L. Zaytseva, T. E. Moskovskaya, E. V. Gromov and J. Schirmer, J. Phys. Chem. A, 2009, 113, 5736-5742.

5 M. Szczesniak, K. Szczepaniak, J. S. Kwiatkowski, K. KuBulat and W. B. Person, J. Am. Chem. Soc., 1988, 110, 8319-8330; M. J. Nowak, L. Lapinski and J. Fulara, Spectrochim. Acta, 1989, 45A, 229-242; E. D. Radchenko, G. G. Sheina, N. A. Smorygo and Yu. P. Blagoi, J. Mol. Struct., 1984, 116, 387-396.

6 M. Y. Choi, F. Dong and R. E. Miller, Philos. Trans. R. Soc. London, Ser. A, 2005, 363, 393-413.

7 M. J. Frisch, G. W. Trucks, H. B. Schlegel, G. E. Scuseria, M. A. Robb, J. R. Cheeseman, J. A. Montgomery, Jr., T. Vreven, K. N. Kudin, J. C. Burant, J. M. Millam, S. S. Iyengar, J. Tomasi, V. Barone, B. Mennucci, M. Cossi, G. Scalmani, N. Rega, G. A. Petersson, H. Nakatsuji, M. Hada, M. Ehara, K. Toyota, 
R. Fukuda, J. Hasegawa, M. Ishida, T. Nakajima, Y. Honda, O. Kitao, H. Nakai, M. Klene, X. Li, J. E. Knox, H. P. Hratchian, J. B. Cross, V. Bakken, C. Adamo, J. Jaramillo, R. Gomperts, R. E. Stratmann, O. Yazyev, A. J. Austin, R. Cammi, C. Pomelli, J. Ochterski, P. Y. Ayala, K. Morokuma, G. A. Voth, P. Salvador, J. J. Dannenberg, V. G. Zakrzewski, S. Dapprich, A. D. Daniels, M. C. Strain, O. Farkas, D. K. Malick,
A. D. Rabuck, K. Raghavachari, J. B. Foresman, J. V. Ortiz, Q. Cui, A. G. Baboul, S. Clifford, J. Cioslowski, B. B. Stefanov, G. Liu, A. Liashenko, P. Piskorz, I. Komaromi, R. L. Martin, D. J. Fox, T. Keith, M. A. Al-Laham, C. Y. Peng, A. Nanayakkara, M. Challacombe, P. M. W. Gill, B. G. Johnson, W. Chen, M. W. Wong, C. Gonzalez and J. A. Pople, GAUSSIAN 03 (Revision C.02), Gaussian, Inc., Wallingford, CT, 2004. 